\title{
Recursos digitales para la enseñanza y el aprendizaje de la historia
}

Aurora Terán Fuentes

\section{Resumen}

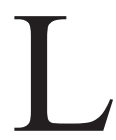
a incorporación de los recursos digitales con fines educativos implica replantear la propia práctica docente, así como la didáctica a nivel general, tanto en los diferentes campos del conocimiento, como en los diversos niveles educativos; para el caso de la disciplina de la historia, se cuenta con una serie de alternativas digitales para fomentar aprendizajes, siempre y cuando sean parte de una planeación y cobren sentido dentro del curso que se imparta; ejemplos serían: fomentar la inteligencia espacial y visual a través de la producción de mapas o comprender la dimensión temporal por medio de la elaboración de líneas del tiempo, ambos recursos trabajados de forma gratuita $y$ online.

Palabras clave: aprendizaje de la historia, enseñanza de la historia, recursos digitales educativos, creatividad.

\section{Introducción}

En la enseñanza y aprendizaje de la historia, como en otras disciplinas o carreras del nivel superior, se están incorporando recursos relacionados con las TIC, que no necesariamente vienen a sustituir formas didácticas tradicionales, pero sí se pueden complementar o enriquecer en los ambientes áulicos. Por ejemplo, quienes entran a estudiar historia en las universidades claramente deben leer -y mucho-, y tienen que desarrollar la capacidad para escribir, porque el oficio de historiar se relaciona con la escritura, es decir, coloquialmente el historiador cuenta y escribe relatos; claro está, con una perspectiva científica, historiográfica y con información obtenida del trabajo en diversos acervos documentales. Por ende, la lectura y revisión de fuentes secundarias y primarias no se puede sustituir, al igual que el ejercicio de escritura concretado en ensayos, reportes, reseñas, críticas, síntesis y resúmenes, hasta llegar a informes, ponencias, tesinas y tesis.

No obstante, en algunas ocasiones se le puede solicitar a un estudiante que en lugar de realizar una síntesis de una lectura en un documento en Word, produzca una infografía online, o en lugar de pedirle un mapa conceptual o mental en su libreta, igualmente se apoye en diversos recursos digitales. A pesar de que los jóvenes pueden llegar a ser considerados como "nativos digitales", no quiere decir que cuenten con tales habilidades para utilizarlas de manera efectiva en su proceso de aprendizaje, esto es, diversos medios de la llamada "Era Digital". Por ello, su uso promoverá que el alumno adquiera competencias digitales con fines educativos.

El objetivo de este artículo es presentar algunas herramientas digitales de utilidad, centradas en el proceso de aprendizaje de la historia, con algunas de sus características y ejemplos de productos.

\section{Dos recursos viejos y novedosos para el aprendizaje de la historia}

En la carrera y disciplina de la historia se trabaja en relación a dos preguntas generales: “¿cuándo?” y “¿dónde?”, la primera pregunta refiere a la dimensión temporal y la segunda a la dimensión espacial. Hay dos recursos que han acompañado la enseñanza de la historia, me refiero a las líneas del tiempo (también cronologías) y a los mapas. Regularmente, en los libros de historia para niños y adolescentes vienen ambos, son material didáctico clásico de la disciplina; en el nivel superior se continúan utilizando, sobre todo con énfasis en la enseñanza; es decir, es un material de apoyo para los docentes, de provecho en sus exposiciones o para discutir un tema, siempre con la intención de ubicar en tiempo y espacio un acontecimiento, una tendencia, un proceso o un personaje. Sin embargo, desde la perspectiva del aprendizaje, los estudiantes son los que producirían los mapas y las líneas del tiempo, y ahora se pueden elaborar y diseñar utilizando una diversidad de recursos digitales.

No hay que olvidar que parte del campo laboral y profesional de un historiador es la docencia, por tal razón, desde su paso como estudiante por la Universidad podría comenzar a elaborar material que, en un primer momento, 
sería para su propia formación y respondería a requerimientos de los contenidos o procedimientos de una determinada asignatura, pero también se le proporcionarían herramientas para generar material educativo digital, o ir más allá, al diseño de objetos de aprendizaje.

En lo que toca a las líneas del tiempo, son representaciones gráficas para la compresión del tiempo histórico. Díaz Barriga (1998) las resume de la siguiente manera: "el orden de acontecimientos dentro de una secuencia [...], el agrupamiento de acontecimientos concurrentes en el tiempo [...], y el establecimiento de un sentido de continuidad entre el pasado y el presente" (p. 50).

Las líneas del tiempo son [una] forma de representación gráfica de la información, a través de la cual se destacan en una línea recta graduada en unidades de tiempo, hechos y/o momentos históricos relevantes. Las líneas del tiempo permiten ordenar visualmente una secuencia de eventos temporales o hechos que requieren de un orden cronológico, de tal forma que se facilite visualizar con claridad la relación temporal entre ellos (Villalustre y Del Moral, 2010: 23).

Algunas de las aplicaciones que nos permiten construir líneas del tiempo son "Tiki-Toki" y "Timetoast" (para ambos es necesario registrarse), las cuales proporcionan herramientas para generar un producto en el que se presenta una secuencia temporal, posibilita definir las unidades de tiempo, escribir el acontecimiento, subir imágenes y redactar reseñas de cada suceso histórico con creatividad, de manera que resulten atractivas para quien las elabore y consulte, de una forma interactiva. Las líneas del tiempo siempre implican la creatividad y son atractivas visualmente, sin olvidar que su uso didáctico ayuda en los procesos de comprensión del tiempo y su división (siglos, eras, épocas y etapas, entre otros), en correspondencia con sucesos y hechos históricos.

Respecto a los mapas, permiten la ubicación de los eventos históricos para su comprensión en la dimensión espacial porque son representaciones del planeta.

El mapa es, por esencia, un documento versátil y esta cualidad le permite, por un lado, acoger en su ámbito cualquier tema que involucre la representación del espacio y, por el otro, como una respuesta, emite una imagen correspondiente del territorio cartografiado, mismo que es susceptible de ser interpretada (Delgado, 2002: 333).
Aquel sujeto que se esté preparando en la disciplina histórica también debe contar con un vasto conocimiento de geografía, con el fin de comprenderla y explicarla dentro del devenir histórico, por ejemplo, la división política de una nación o de un continente cambia a lo largo de la historia, lo que ha implicado el reajuste de fronteras, la creación de países, la fragmentación de otros, así como invasiones. Tal es el caso de nuestro país: México, cuando era Nueva España en el tiempo de la Colonia, territorialmente era mucho más grande que en la actualidad, los mapas permitirían observar y analizar el gran tamaño que tenía la colonia española, así como la definición de las fronteras, los procesos de pérdida de territorio y las divisiones políticas con el correr de los años y con el paso a una nación independiente.

Un sitio web que sería de mucha utilidad al historiador, maestro o estudiante de historia es "MapChart", el cual sirve para la elaboración de mapas por continente, regiones o países; permite definir divisiones políticas o quitarlas, y a través de una gama de colores hacer énfasis en las partes que se necesitan mostrar; cada color utilizado genera automáticamente el campo para escribir la leyenda, acotación o explicación. Cuando se finaliza el diseño, "MapChart"permite descargar el producto en formato de imagen PNG.

Las líneas del tiempo y los mapas, dos tipos de material didáctico de apoyo a los maestros durante muchos años, no pierden vigencia y pertinencia, no obstante, a través de programas novedosos, implican retos para el trabajo en el aula, con un enfoque centrado en procesos de aprendizaje.

\section{Otros recursos digitales de utilidad}

Existen otras herramientas digitales de gran apoyo y utilidad (no solamente para la enseñanza y aprendizaje de la historia, sino para cualquier asignatura o disciplina), como "Lucidchart", con la que se elaboran mapas conceptuales, producto valioso en el aprendizaje de la historia por la gran cantidad de lectura que realizan los estudiantes en todos sus cursos, por ejemplo, en la revisión de libros sobre teoría de la historia o historiografía, un reporte o evidencia de lectura puede ser un mapa conceptual, que se traduce a un ejercicio cognitivo en el cual, cuando se comprenden los textos, en consecuencia, se es capaz de relacionar y jerarquizar conceptos y darles un sentido a partir de una red o malla de términos.

"Piktochart" y "Canva" (permiten suscripciones gratuitas y de pago), son dos programas de diseño para la elaboración de infografías, con el objetivo de presentar in- 
formación verbal y visual de forma sintética y creativa, lo cual representa una estrategia diferente para construir una evidencia de lectura, mostrar un acontecimiento o personajes históricos. Ambos programas permiten comenzar a diseñar, utilizando fondos, colores, figuras, símbolos, textos e imágenes, esto sobre plantillas de boletines, folletos, carteles, postales y cuadernillos, entre otros, o a partir de una hoja en blanco; además, "Piktochart" ofrece la posibilidad de trabajar mapas y gráficos directamente; y "Canva", por otra parte, cuenta con una interfaz que puede resultar más amigable. Por ejemplo al estudiante se le podría solicitar un boletín (periódico) de una época determinada, generar noticias, entrevistar a personajes de la época, redactar una crónica, exponer usos y costumbres, con un estilo periodístico.

Por otro lado, es importante considerar que los productos generados pueden integrarse o complementarse, por ejemplo, los mapas generados en "MapChart" se suben como imagen a "Piktochart" y "Canva", y se les incluyen otros elementos como flechas, personajes, globos de diálogos y mucho más; de la misma forma, un mapa conceptual generado en "Lucidchart". Son muchos los recursos: "Linoit" sirve para construir murales digitales, de utilidad para efemérides, noticias o anuncios, o qué tal elaborar un cómic en el que se explique la educación socialista en tiempos del presidente Lázaro Cárdenas en "Make Beliefs Comix", o es posible hacerlo nuevamente en "Canva".

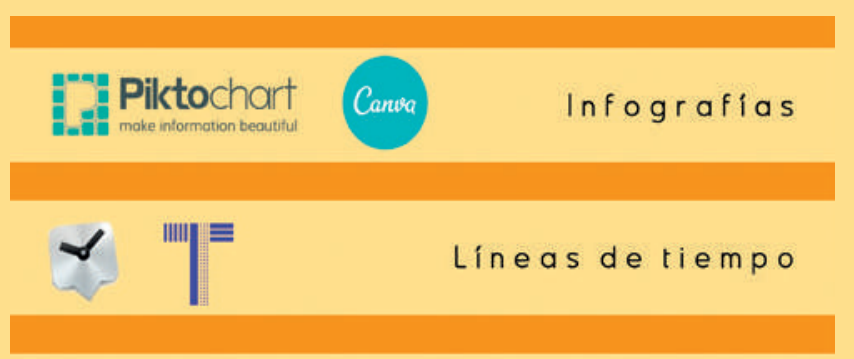

\&. Lucidchart Mapas conceptuales

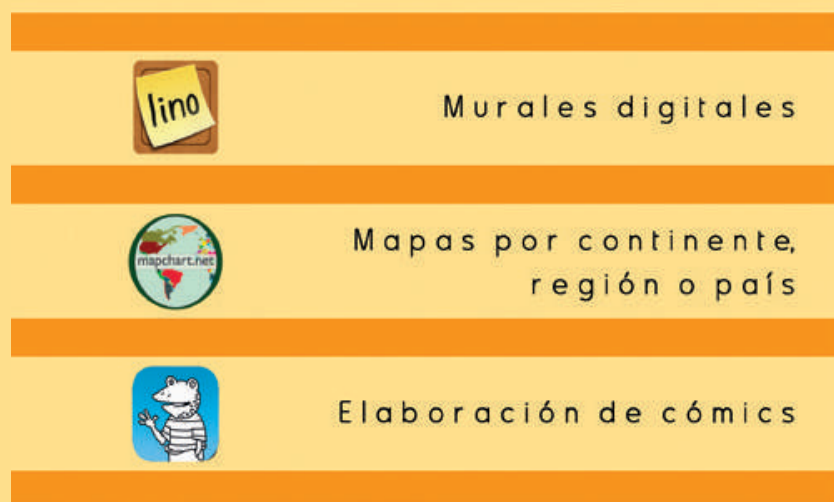

Todas las herramientas descritas son online y gratuitas, para "Piktochart", "Canva", "Lucidchart", "Linoit", "Timetoast", "Make Beliefs Comix" y "Tiki-Toki”, únicamente es necesario registrarse dentro de los programas para obtener una cuenta, por ende, una de las ventajas consiste en que los trabajos son editables y reutilizables; "MapChart" no requiere registro, por tal razón, el producto tendrá que comenzarse a crear y finalizarse en ese momento, pues no podrá ser guardado para editarlo posteriormente.

\section{Conclusiones}

Son muchas las posibilidades ofrecidas desde internet para la generación de productos digitales con el objetivo de fortalecer aprendizajes, a la par de la adquisición de habilidades digitales y el fomento al trabajo creativo. El estudiante podría construir un portafolio de evidencias digitales, por ejemplo, en la medida que se estudia un acontecimiento en el aula, ir generando una carpeta de infografías con énfasis en mapas, como los viajes de Cristóbal Colón, las revoluciones de la época contemporánea o las rutas de la insurgencia en México, entre muchos otros temas.

Lo que se debe tener en cuenta al decidir incorporar la elaboración de productos digitales es saber que el grupo con el que se va a trabajar cuente con lo básico, como una computadora y acceso a internet; además de ofrecer una pequeña inducción cuando se trabaje con una aplicación, sitio web, programa o recurso digital por primera vez; y siempre la recomendación de incluir referencias o créditos de textos, imágenes y recursos utilizados.

\section{Fuentes de consulta}

Delgado, E. (2002). El mapa, importante medio de apoyo para la enseñanza de la historia. Revista Mexicana de Investigación Educativa, 7(15), 331-356. Recuperado el 15 de julio de 2018, de: https://bit.ly/2CT9TLW.

Díaz Barriga, F. (1998). Una aportación a la didáctica de la historia. La enseñanza-aprendizaje de habilidades cognitivas en el bachillerato. Perfiles Educativos, 20(83), 40-66. Recuperado el 17 de julio de 2018, de: www. iisue.unam.mx/perfiles/descargas/pdf/1998-82-40-66.

Villalustre, L. y Del Moral, E. (2010). Mapas conceptuales, mapas mentales y líneas temporales: objetos "de" aprendizaje y "para" el aprendizaje en Ruralnet. Revista Latinoamericana de Tecnología Educativa, 9(1), 15-27. Recuperado el 17 de julio de 2018, de: https:// dialnet.unirioja.es/descarga/articulo/3268848.pdf. 